\title{
Association of serum potassium concentration with mortality and ventricular arrhythmias in patients with acute myocardial infarction: A systematic review and meta-analysis
}

European Journal of Preventive Cardiology

\author{
Miriam Giovanna Colombo ${ }^{1,2, *}$, Inge Kirchberger ${ }^{1,2,3,4, *}$, \\ Ute Amann ${ }^{1,2,3}$, Lisa Dinser ${ }^{1,2}$ and Christa Meisinger ${ }^{1,2,3}$
}

\begin{abstract}
Background: Challenging clinical practice guidelines that recommend serum potassium concentration between $4.0-5.0 \mathrm{mEq} / \mathrm{L}$ or $\geq 4.5 \mathrm{mEq} / \mathrm{L}$ in patients with acute myocardial infarction, recent studies found increased mortality risks in patients with a serum potassium concentration of $\geq 4.5 \mathrm{mEq} / \mathrm{L}$. Studies investigating consequences of hypokalemia after acute myocardial infarction revealed conflicting results. Therefore, the aim of this systematic review and metaanalysis was to combine evidence from previous studies on the association of serum potassium concentration with both short and long-term mortality as well as the occurrence of ventricular arrhythmias.

Design: Systematic review and meta-analysis.

Methods: A structured search of MEDLINE and EMBASE databases yielded 23 articles published between 1990 and January 2017 that met the inclusion criteria. Study selection, data extraction and quality assessment were carried out by three reviewers. Random effects models were used to pool estimates across the included studies and sensitivity analyses were performed when possible.

Results: Twelve studies were included in the meta-analysis. Both pooled results from six studies investigating short-term mortality and from five studies examining long-term mortality revealed significantly increased risks in patients with serum potassium concentrations of $<3.5 \mathrm{mEq} / \mathrm{L}, 4.5-<5.0 \mathrm{mEq} / \mathrm{L}$ and $\geq 5.0 \mathrm{mEq} / \mathrm{L}$ after acute myocardial infarction. In addition, a serum potassium concentration of $<3.5 \mathrm{mEq} / \mathrm{L}$ was significantly associated with the occurrence of ventricular arrhythmias.

Conclusions: Mortality, both short and long term, and the occurrence of ventricular arrhythmias in patients with acute myocardial infarction seem to be negatively associated with hypokalemic serum potassium concentration. There is evidence for adverse consequences of serum potassium concentrations of $\geq 4.5 \mathrm{mEq} / \mathrm{L}$. Due to the heterogeneity among existing studies, further research is necessary to confirm the need to change clinical practice guidelines.
\end{abstract}

\section{Keywords}

Myocardial infarction, hypokalemia, hyperkalemia, mortality, arrhythmia, meta-analysis

Received 22 November 2017; accepted 26 January 2018

\footnotetext{
'MONICA/KORA Myocardial Infarction Registry, Central Hospital of Augsburg, Germany

${ }^{2}$ Institute of Epidemiology II, Helmholtz Zentrum München, German Research Center for Environmental Health $(\mathrm{GmbH})$, Germany

${ }^{3}$ Chair of Epidemiology, UNIKA-T, Ludwig-Maximilians-Universität München, Germany
}

${ }^{4}$ Centro de Investigación Biomédica en Red, Enfermedades Cardiovasculares (CIBERcv), Spain

*The first two authors contributed equally

Corresponding author:

Inge Kirchberger, Chair of Epidemiology, UNIKA-T, Neusässer Str. 47, 86I56 Augsburg, Germany.

Email: i.kirchberger@unika-t.de 


\section{Introduction}

Hypokalemia (serum potassium concentration $(\mathrm{SPC})<3.5 \mathrm{mEq} / \mathrm{L})$ and hyperkalemia $\quad(\mathrm{SPC} \geq$ $5.0 \mathrm{mEq} / \mathrm{L}$ ) can have a variety of adverse consequences in patients hospitalised after a cardiovascular event, for instance higher mortality risks or ventricular arrhythmia (VA). ${ }^{1-4}$ For patients with acute myocardial infarction (AMI), clinical practice guidelines recommend SPCs of at least $4.0 \mathrm{mEq} / \mathrm{L},{ }^{4}$ between 4.0 and $5.0 \mathrm{mEq} / \mathrm{L}^{6,7}$ or above $4.5 \mathrm{mEq} / \mathrm{L}^{8}$ However, recent studies in patients with AMI indicated that a SPC of $4.5 \mathrm{mEq} / \mathrm{L}$ or greater was associated with increased inhospital and 3-year mortality, respectively. ${ }^{9-11}$ Moreover, results from available studies investigating the consequences of hypokalemia were conflicting. Hypokalemia was found to be associated with $\mathrm{VA}^{9,12-16}$ and higher mortality ${ }^{9,10,15}$ in some studies, whereas others did not find increased risks for $\mathrm{VA}^{10,17-19}$ or mortality ${ }^{11,16,19}$ in patients with AMI.

So far, although a number of studies are available, it is difficult to reach an evidence-based conclusion to suggest SPC might have adverse consequences in AMI patients. Thus the objective of this study was to provide a systematic review and meta-analysis of studies assessing the association of SPC with both short and long-term mortality as well as VA in patients with AMI.

\section{Methods}

The meta-analysis was conducted in accordance with the preferred reporting items for systematic reviews and meta-analyses (PRISMA) statement. ${ }^{20}$

\section{Eligibility criteria}

The study's inclusion criteria were as follows: (a) subjects with AMI; (b) assessment of SPC; (c) assessment of mortality and/or VA; (d) humans.

\section{Definition of endpoints}

Short-term mortality includes assessments of all-cause mortality within 6 months after AMI whereas longterm mortality was defined as all-cause mortality later than 6 months. VA was defined as abnormal rapid heart rhythms that originate in the lower chambers of the heart, such as ventricular tachycardia (VT) or ventricular fibrillation (VF).

\section{Data sources and search strategy}

The MEDLINE and EMBASE databases (1990 to 25 January 2017) were searched for studies that examined the association of SPC with mortality and/or VA in patients with AMI using the following $\mathrm{MeSH}$ headings/text words: potassium/blood; hypokalemia; hyperkalemia; mortality; arrhythmia, cardiac; tachycardia, ventricular; fibrillation, ventricular. The detailed strategy is shown in Supplementary Tables 1 and 2. No language restrictions were applied. Electronic searches were supplemented with a review of the reference lists of retrieved articles.

\section{Study selection}

The screening of titles and abstracts for eligibility was carried out by two authors independently (MGC and LD, MGC and IK, MGC and UA). Disagreements were solved by discussion or by reading the full text article. The full texts were also read independently by two authors (MGC and IK, MGC and UA). Disagreements were solved by discussion. The decision as to which studies to include in the meta-analysis was based on the quality assessment and on the SPC category used as reference to ensure comparability of effect sizes across studies. Studies scoring higher than five in the quality assessment were included.

\section{Data extraction}

Two authors each (MGC and IK, MGC and UA) extracted and collected data independently. Disagreements were resolved by discussion. The following data were abstracted: publication information (authors, title, journal, publication year); study characteristics (design, objectives, data source, data collection period, inclusion/exclusion criteria); patient characteristics (sample size, age, sex, event rates (short and longterm mortality and VA); methods (AMI definition, SPC measurement and classification, statistical methods, confounders); and reported outcomes (definition, assessment, effect sizes). Studies reported SPC in milliequvalents per litre $(\mathrm{mEq} / \mathrm{L})$ or millimoles per liter $(\mathrm{mmol} / \mathrm{L})$. Both units can be used interchangeably in this case, but for the sake of simplicity $\mathrm{mEq} / \mathrm{L}$ will be used throughout this article.

\section{Quality assessment}

Quality assessment was performed using a selection of 12 items from the checklist for measuring study quality $^{21}$ which are appropriate to assess the quality of observational studies. This checklist was complemented by two items from the Cochrane Collaboration's tool for assessing risk of bias" ('Were incomplete outcome data adequately assessed?' and 'Was the study apparently free of other problems that could put it at risk of bias?') as well as three self-developed criteria ('Were withdrawals/drop-outs reported?', 'Were data 
collection methods clearly described?' and 'Were appropriate categories chosen to classify SPC?'). Each of the 17 items was scored ' 1 ' (yes) or ' 0 ' (no or unable to determine) and a summary score was built ranging from 0 (lowest quality) to 17 (highest quality).

Quality assessments were each performed by two authors (MGC and IK, MGC and UA) independently. Disagreements were resolved by discussion.

\section{Meta-analysis}

Meta-analysis was performed using the comprehensive meta-analysis software version 3.0. ${ }^{23}$ In a conservative approach, the random effects model which allows for variation of true effects across studies was chosen. Heterogeneity was assessed by the $I^{2}$ statistics. As the number of included studies was less than 10 for each of the three endpoints, we refrained from any tests on publication bias, which may have too low a power to distinguish chance from reality. ${ }^{24}$

\section{Results}

The literature search revealed 2285 publications (see Figure 1). We identified 23 articles fulfilling our inclusion criteria (see Table 1). Apart from one study, ${ }^{15}$ all of them were observational studies. Five papers investigated the association between SPC and all three outcomes (short, long-term mortality and VA). The summary quality scores assessed for each paper are provided in Table 1. Overall, only three studies did not reach a quality score higher than five. ${ }^{25-27}$ Adjustment for relevant confounders was a crucial determinant during quality assessment. Supplementary Table 3 provides an overview of the confounders considered in each of the included studies.

\section{Short-term mortality}

The literature search yielded 12 studies which investigated the association between SPC and short-term mortality (see Table 2). In three out of six studies that

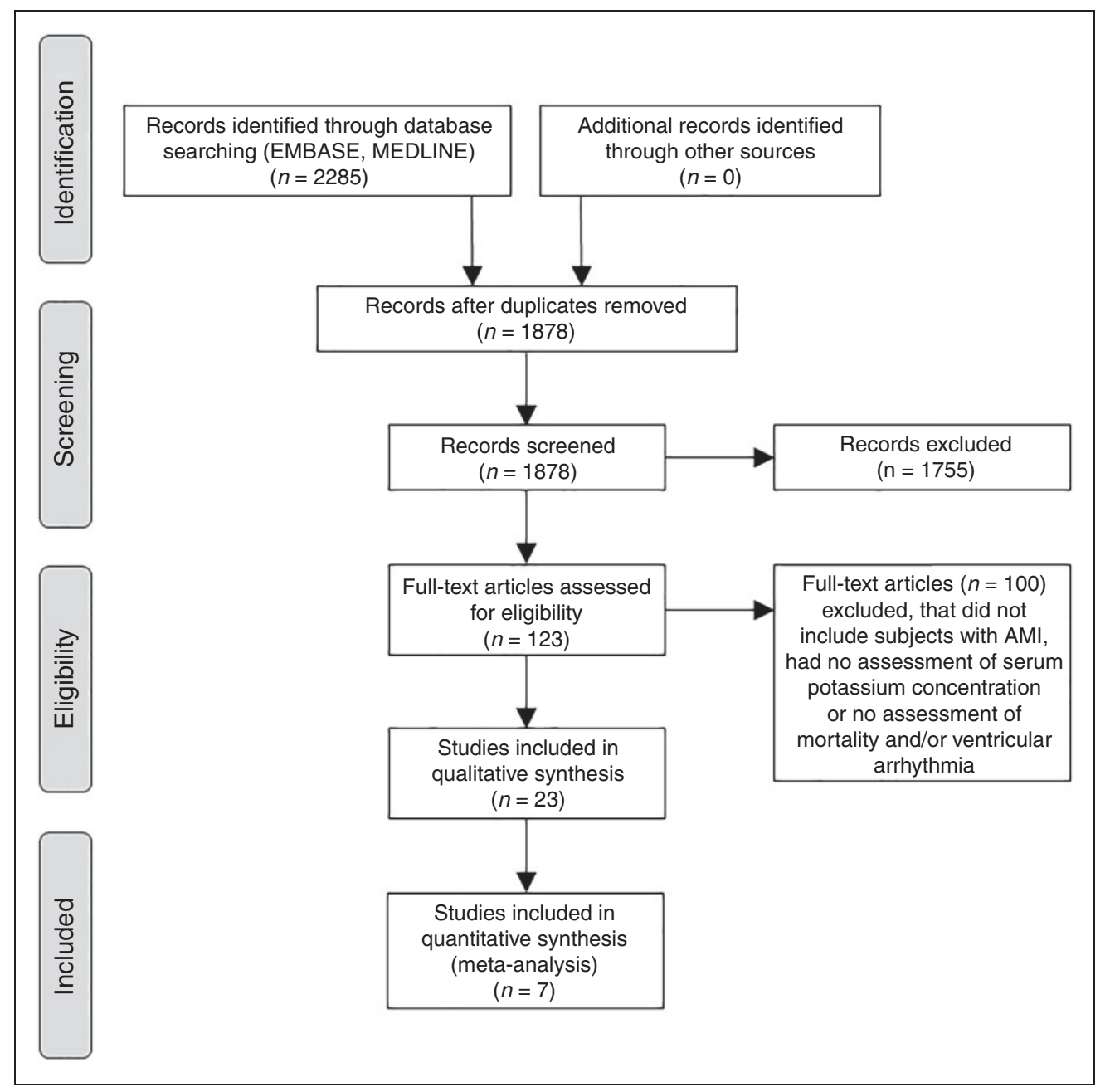

Figure I. Flow diagram. 
窟产产

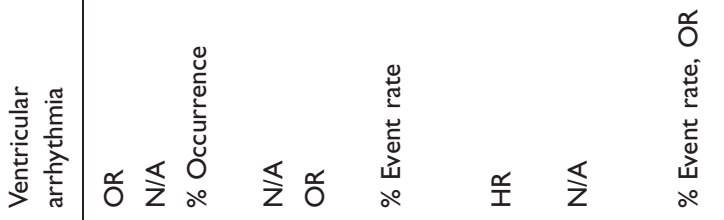

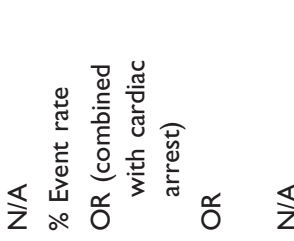

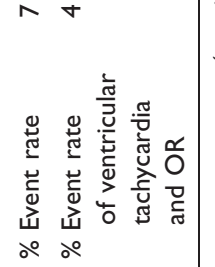

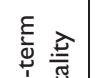

要

$\stackrel{\leftrightarrow}{\check{Z}} \stackrel{\frac{x}{I}}{\dddot{1}} \stackrel{0}{0}$

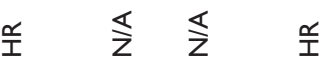

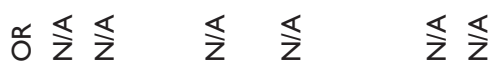

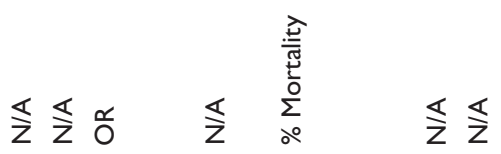

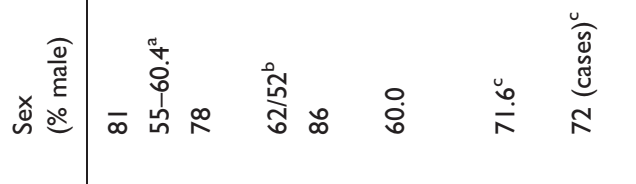
a 虫

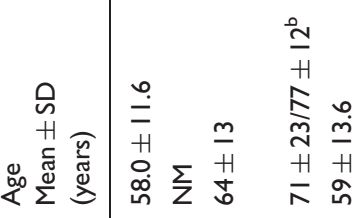<smiles>C1CCCC1</smiles>

离

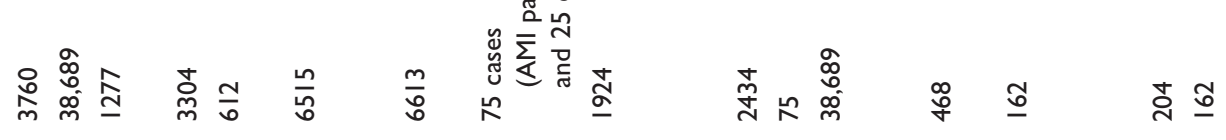

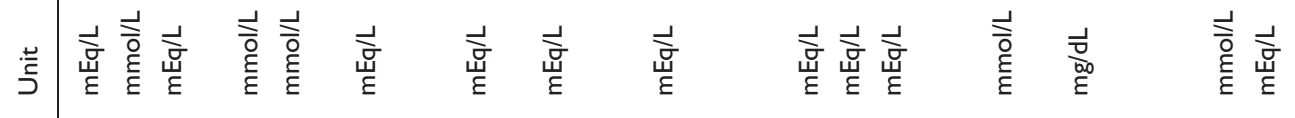

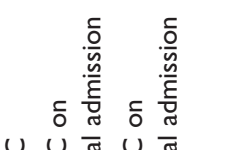

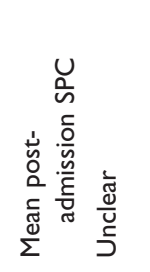

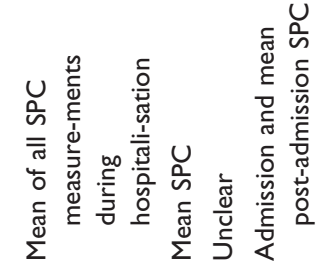

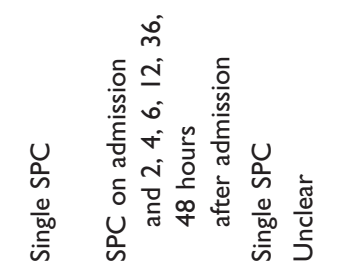




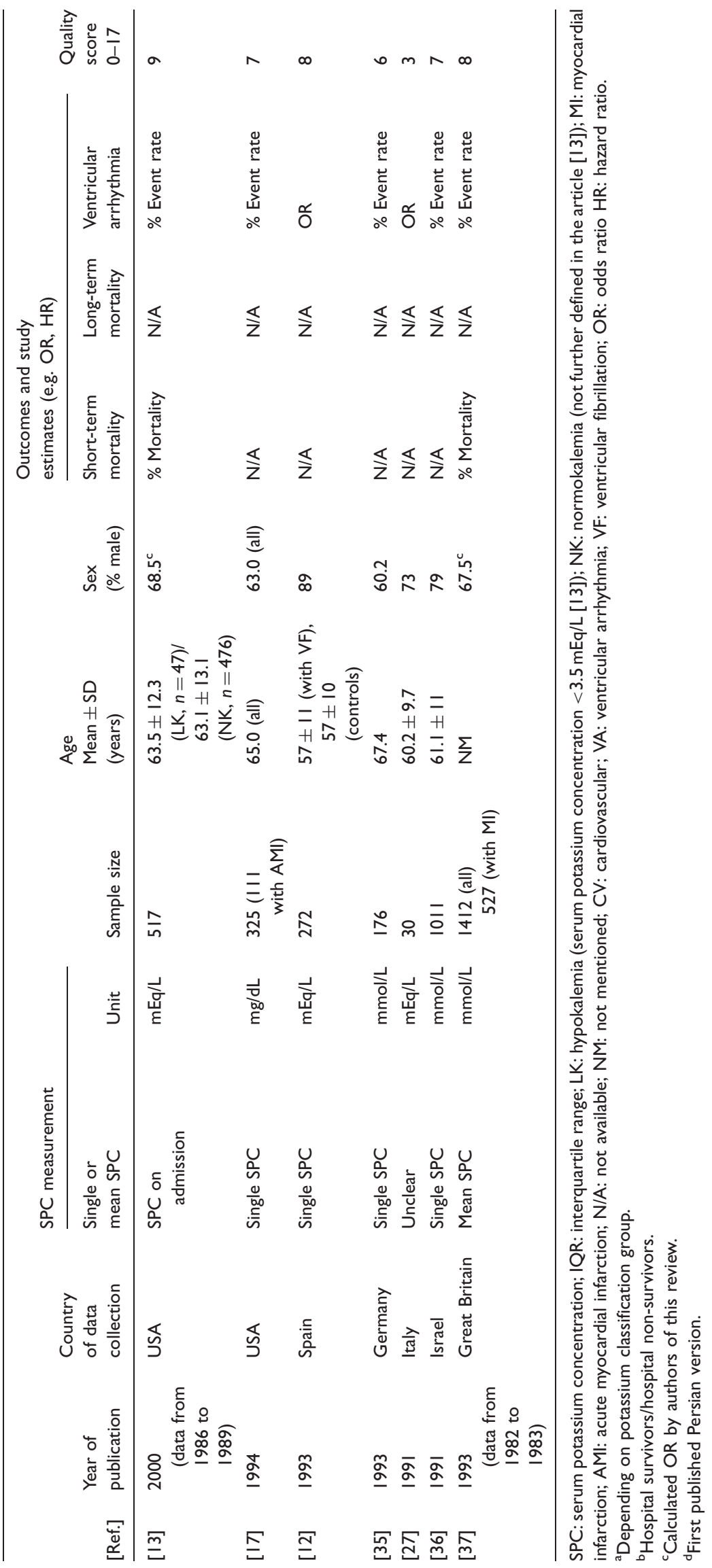




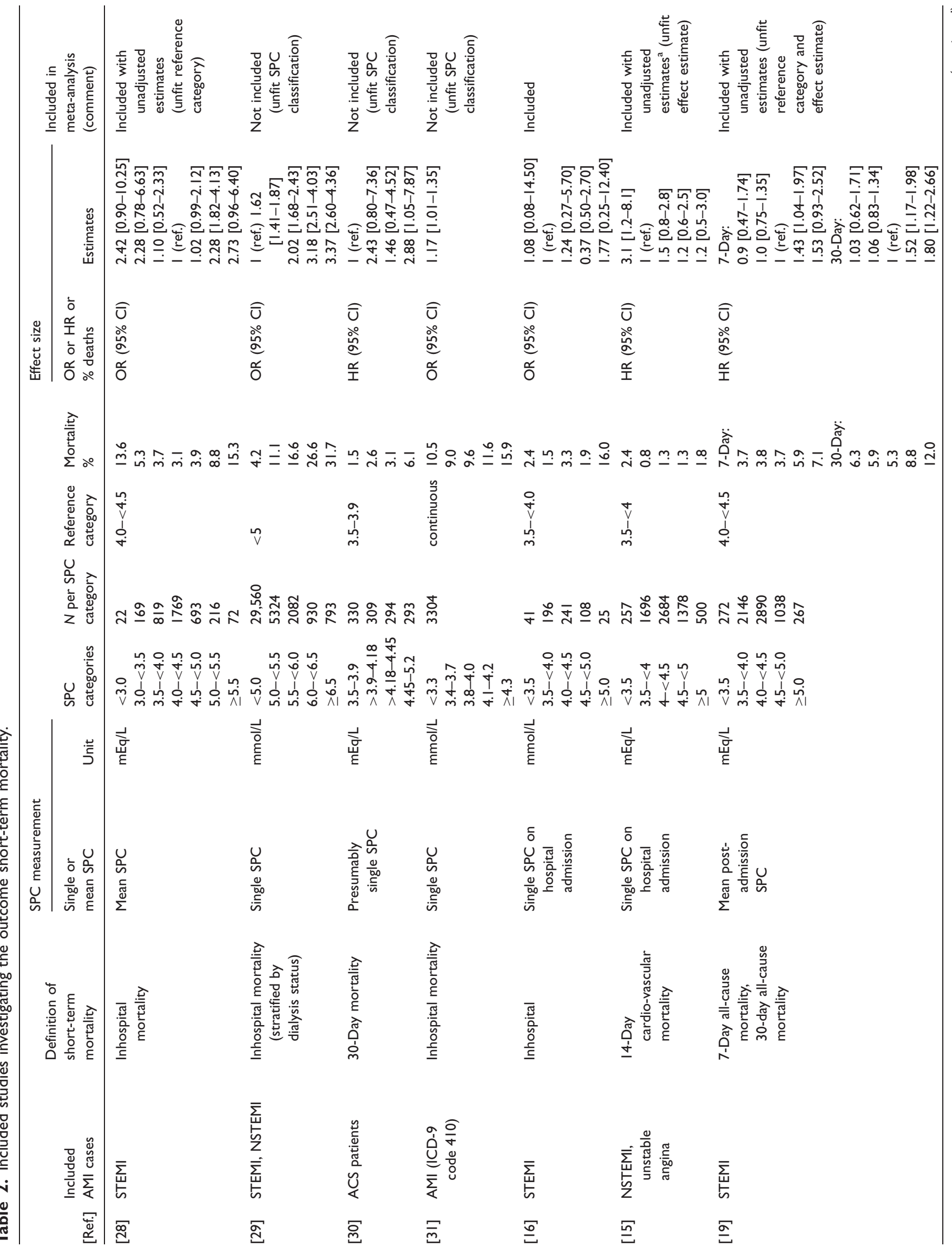




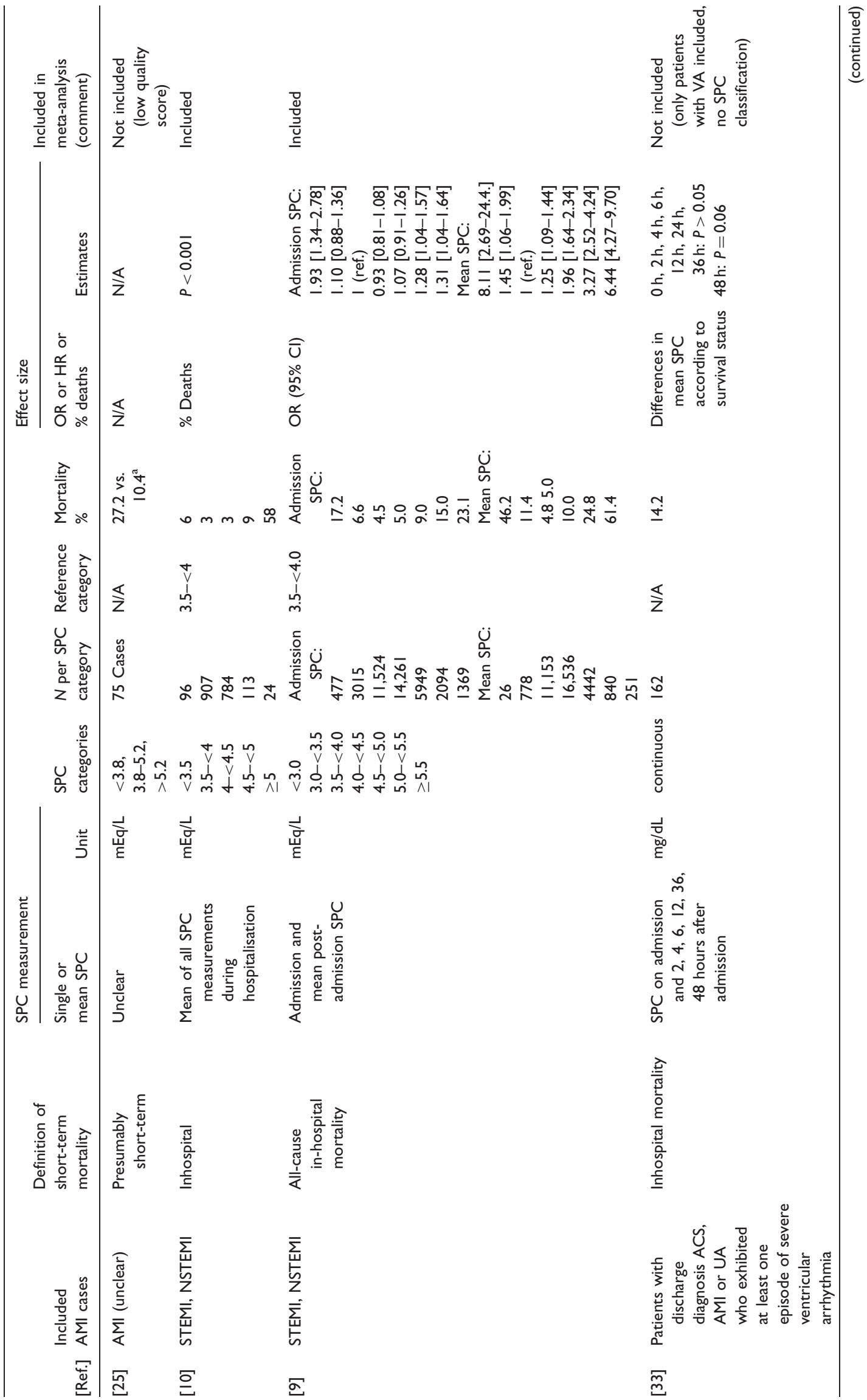




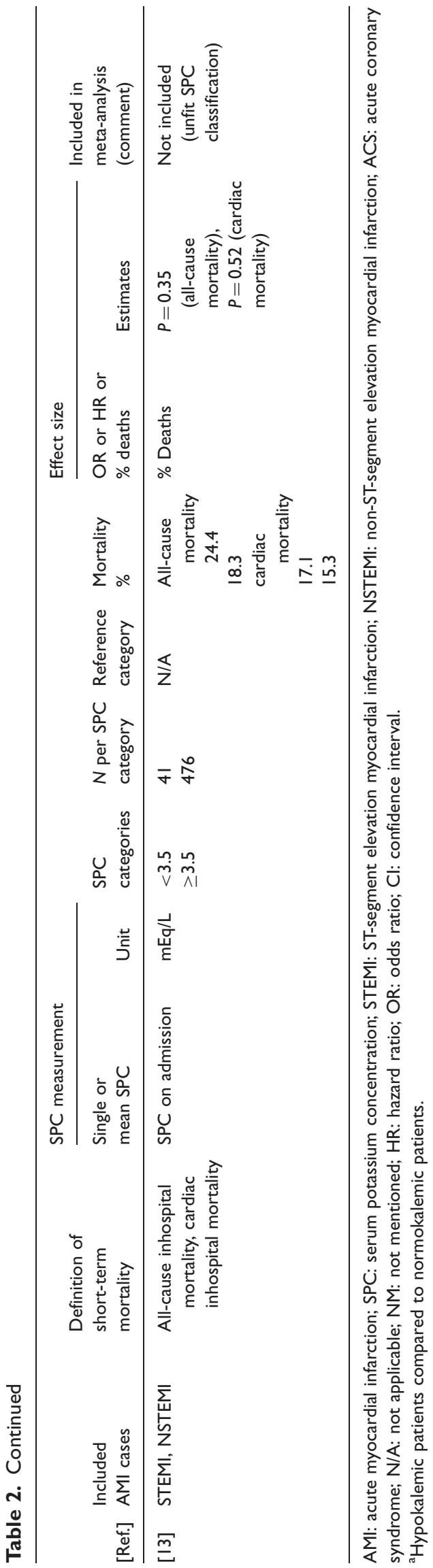

provided a detailed classification of SPCs, patients with SPC between 3.5 and less than $4.0 \mathrm{mEq} / \mathrm{L}$ showed the lowest, unadjusted short-term mortality risk. ${ }^{9,15,16}$ In the study by Choi et al. ${ }^{10}$ and $\mathrm{Ma}$ et al. ${ }^{19}$ patients with a SPC of 3.5 to less than $4.0 \mathrm{mEq} / \mathrm{L}$ and patients with a SPC of 4.0 to less than $4.5 \mathrm{mEq} / \mathrm{L}$ had a similar risk of dying. In contrast, Keskin et al. ${ }^{28}$ found a slightly higher inhospital mortality $(3.7 \%)$ in patients with a SPC of 3.5 to less than $4.0 \mathrm{mEq} / \mathrm{L}$ than in patients with a SPC of 4.0 to less than $4.5 \mathrm{mEq} / \mathrm{L}(3.1 \%)$.

Six studies were included in the meta-analysis. The SPC category of 3.5 to less than $4.0 \mathrm{mEq} / \mathrm{L}$ served as the reference category. Goyal et al. ${ }^{9}$ and Keskin et al. ${ }^{28}$ provided more than five SPC categories. In order to fit the required number of categories, both the highest and lowest categories were combined with the next lower or next higher category, respectively. In two studies, adjusted odds ratios (ORs) were used as effect sizes, ${ }^{9,16}$ whereas Ma et al. ${ }^{19}$ and Patel et al. ${ }^{15}$ provided hazard ratios (HRs). Choi et al. ${ }^{10}$ reported an unadjusted number of events and Keskin et al. ${ }^{28}$ used a different reference category than required. In order to include all studies in the meta-analysis, the unadjusted number of deaths from the studies of Keskin et al., ${ }^{28}$ Ma et al. ${ }^{19}$ and Patel et al. ${ }^{15}$ was used in the analysis. Four of the included studies investigated inhospital mortality. From Ma et al. ${ }^{19}$ the data on 7-day mortality were included, and from Patel et al. ${ }^{15}$ data on 14-day mortality were included.

The meta-analysis showed pooled ORs for all SPC categories in a U-shaped manner (see Figure 2). Except for the SPC category of 4.0 to less than $4.5 \mathrm{mEq} / \mathrm{L}$, all estimates were significant. There was no indication for heterogeneity in the analyses of the SPC categories of less than $3.5 \mathrm{mEq} / \mathrm{L} \quad\left(I^{2}=0\right)$, but substantial heterogeneity in the analyses of the SPC categories of 4.0 to less than $4.5 \mathrm{mEq} / \mathrm{L}\left(I^{2}=55.6\right), 4.5$ to less than $5.0 \mathrm{mEq} / \mathrm{L}\left(I^{2}=74.3\right)$ and $5.0 \mathrm{mEq} / \mathrm{L}$ or greater $\left(I^{2}=89.7\right)$.

As a sensitivity analysis, the studies which were responsible for most of the heterogeneity were excluded and the pooled effect sizes were re-estimated. In the SPC category of 4.0 to less than $<4.5 \mathrm{mEq} / \mathrm{L}$, the exclusion of Keskin et al. ${ }^{28}$ led to an increase of the pooled OR from 1.06 to 1.17 (95\% confidence interval (CI) 1.03-1.33), which was significant in contrast to the previous analysis with all six studies. Exclusion of Uluganyan et al. ${ }^{16}$ in the SPC category of 4.5 to less than $5.0 \mathrm{mEq} / \mathrm{L}$ resulted in an increase of the pooled effect size from OR 1.53 to 1.60 (95\% CI 1.12-2.27). In the SPC category of $5.0 \mathrm{mEq} / \mathrm{L}$ or greater the exclusion of Choi et al. ${ }^{10}$ led to a reduction of the pooled effect size from OR 3.85 to 2.54 (95\% CI 1.64-3.95), which still remained significant. 


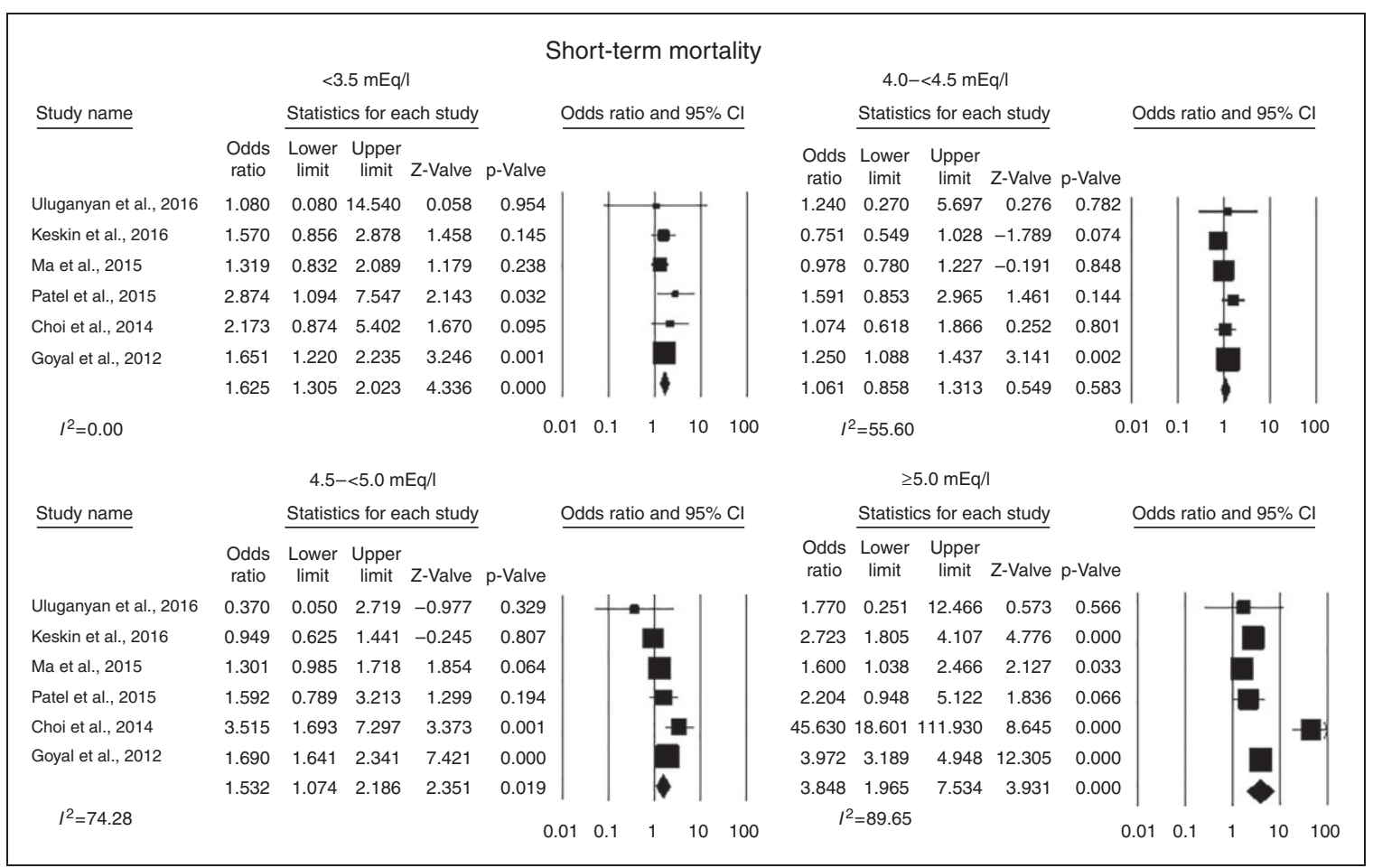

Figure 2. Pooled odds ratios (random effects) of admission serum potassium concentration associated with short-term mortality in patients with acute myocardial infarction.

\section{Long-term mortality}

Seven studies were identified investigating the association of SPC and long-term mortality (see Table 3).

In three out of six studies reporting crude mortality rates per SPC category, patients with SPC between 3.5 and less than $4.0 \mathrm{mEq} / \mathrm{L}$ showed the lowest, unadjusted long-term mortality risk. ${ }^{15,16,30}$ Studies which used a fivelevel SPC classification with values of 3.5 to less than $4.0 \mathrm{mEq} / \mathrm{L}$ as the reference category found a U-shaped association with higher mortality risks for SPC below $3.5 \mathrm{mEq} / \mathrm{L}$, and equal to or above $4.0 \mathrm{mEq} / \mathrm{L}$ with a trend for increased risk estimates with increasing $\mathrm{SPC}^{10,15,16}$ (see Table 3). Shiyovich et al. ${ }^{11}$ and Keskin et al. ${ }^{28}$ classified SPC into seven categories with values of 4.0 to 4.5 or less as the reference category. Shiyovich et al. ${ }^{11}$ showed that a SPC above $4.5 \mathrm{mEq} / \mathrm{L}$ was significantly associated with higher mortality at 6 months, 1 year and 5 years. Keskin et al. ${ }^{28}$ found that SPCs less than $3.5 \mathrm{mEq} / \mathrm{L}$ as well as $\mathrm{SPCs}$ greater than $5.0 \mathrm{mEq} / \mathrm{L}$ were associated with a higher 4-year mortality risk compared with the reference concentration.

As the seven studies used different effect estimates (OR and HR) and different reference categories it was not possible to perform a meta-analysis on the results from the adjusted regression models. Nonetheless, it was possible to include unadjusted ORs with values of 3.5 to less than $4.0 \mathrm{mEq} / \mathrm{L}$ as the reference category from four studies ${ }^{10,11,15,28}$ and adjusted ORs from
Uluganyan et al. ${ }^{16}$ in the meta-analysis. From the study of Shiyovich et al., ${ }^{11}$ the data on 1-year mortality were used. Significantly higher pooled ORs $(1.75,95 \%$ CI 1.28-2.40) were found for SPCs of less than $3.5 \mathrm{mEq} / \mathrm{L}$, for 4.5 to less than $5.0 \mathrm{mEq} / \mathrm{L}$ (OR 1.60 , 95\% CI 1.16-2.19) and for greater than $5.0 \mathrm{mEq} / \mathrm{L}$ (OR 3.29, 95\% CI 2.10-5.15) (see Figure 3).

Moderate heterogeneity was found in the models for SPC of less than $3.5 \mathrm{mEq} / \mathrm{L}\left(I^{2}=46 \%\right)$ and for concentrations of 4.0 to less than $<4.5 \mathrm{mEq} / \mathrm{L}\left(I^{2}=48 \%\right)$. The pooled models on SPC of 4.5 to less than $5.0 \mathrm{mEq} / \mathrm{L}$ and greater than $5.0 \mathrm{mEq} / \mathrm{L}$ indicated substantial heterogeneity $\left(I^{2}=68 \%\right.$ and $75 \%$, respectively).

Sensitivity analyses showed that replacing data on 1year mortality from Shiyovich et al. ${ }^{11}$ with data on 6month mortality from the same study yielded comparable results. The inclusion of unadjusted data instead of adjusted data from Uluganyan et al. ${ }^{16}$ resulted in slightly higher effect estimates.

\section{Ventricular arrhythmia}

The literature search yielded 18 studies which investigated the association between SPC and VA (see Table 4).

A number of studies dichotomised SPC and compared VA rates in SPC groups of less than 3.5, ${ }^{13,32,37}$ less than $3.6^{12}$ or less than $4.0 \mathrm{mEq} / \mathrm{L}^{34}$ with higher 


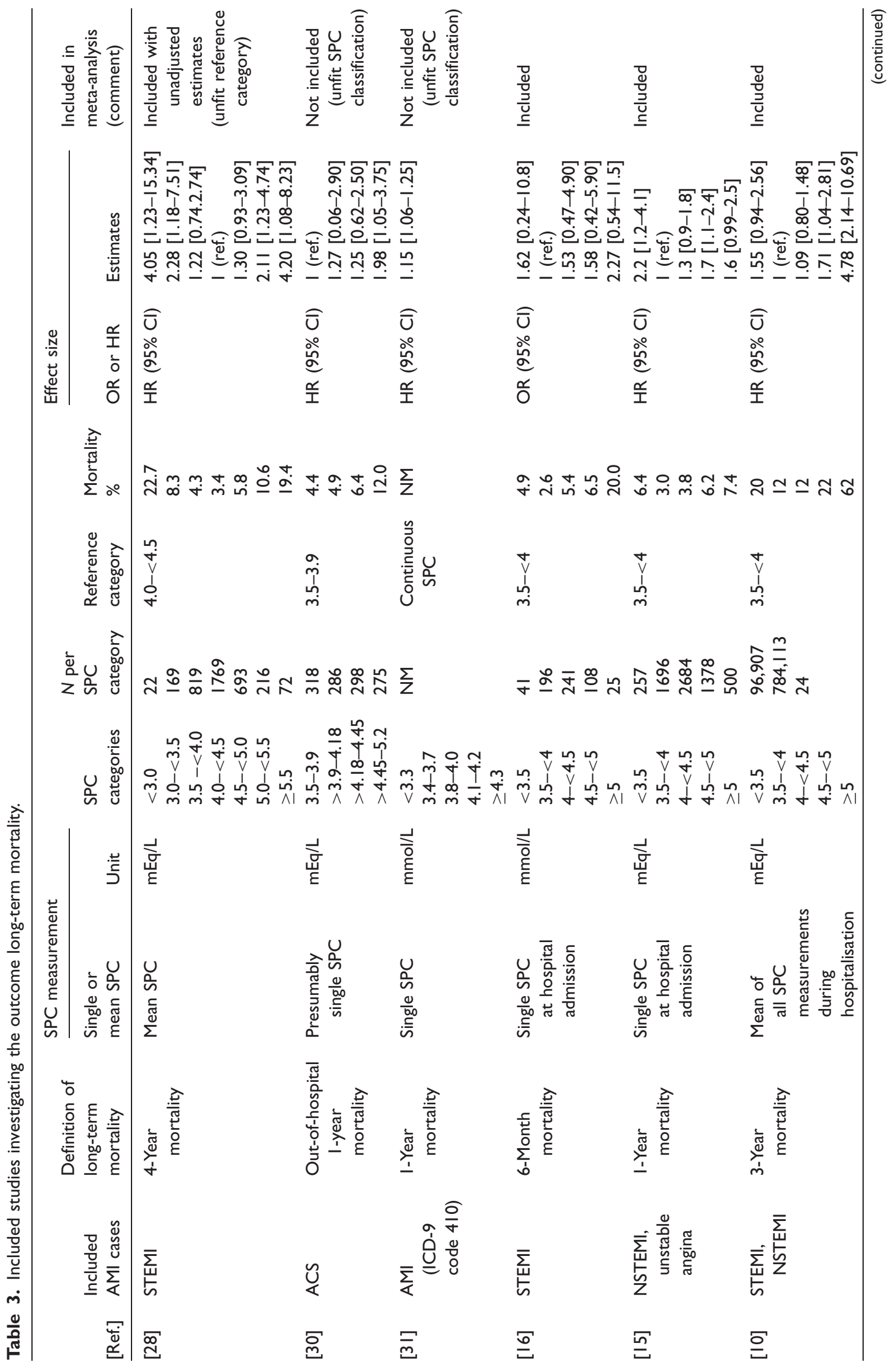




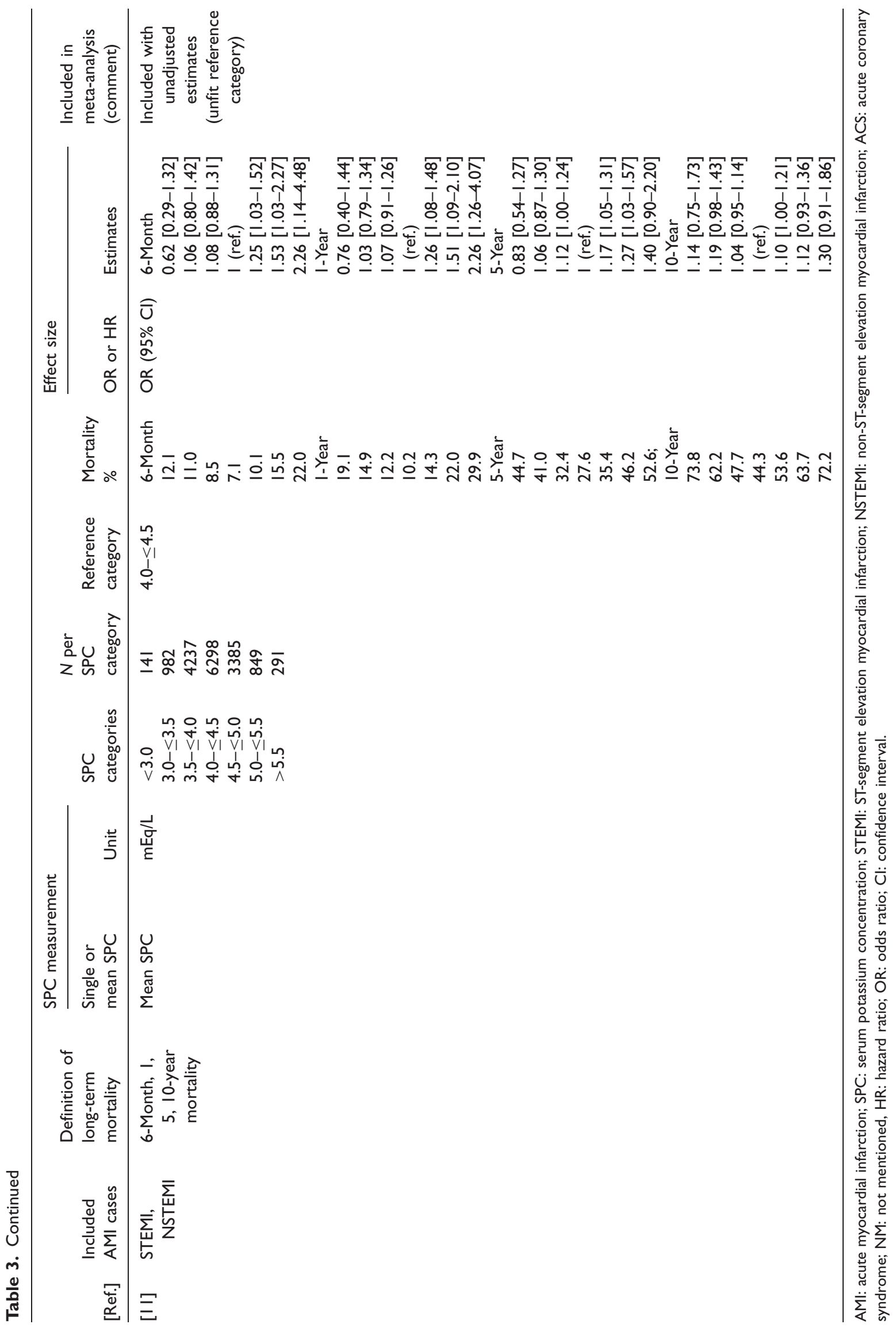




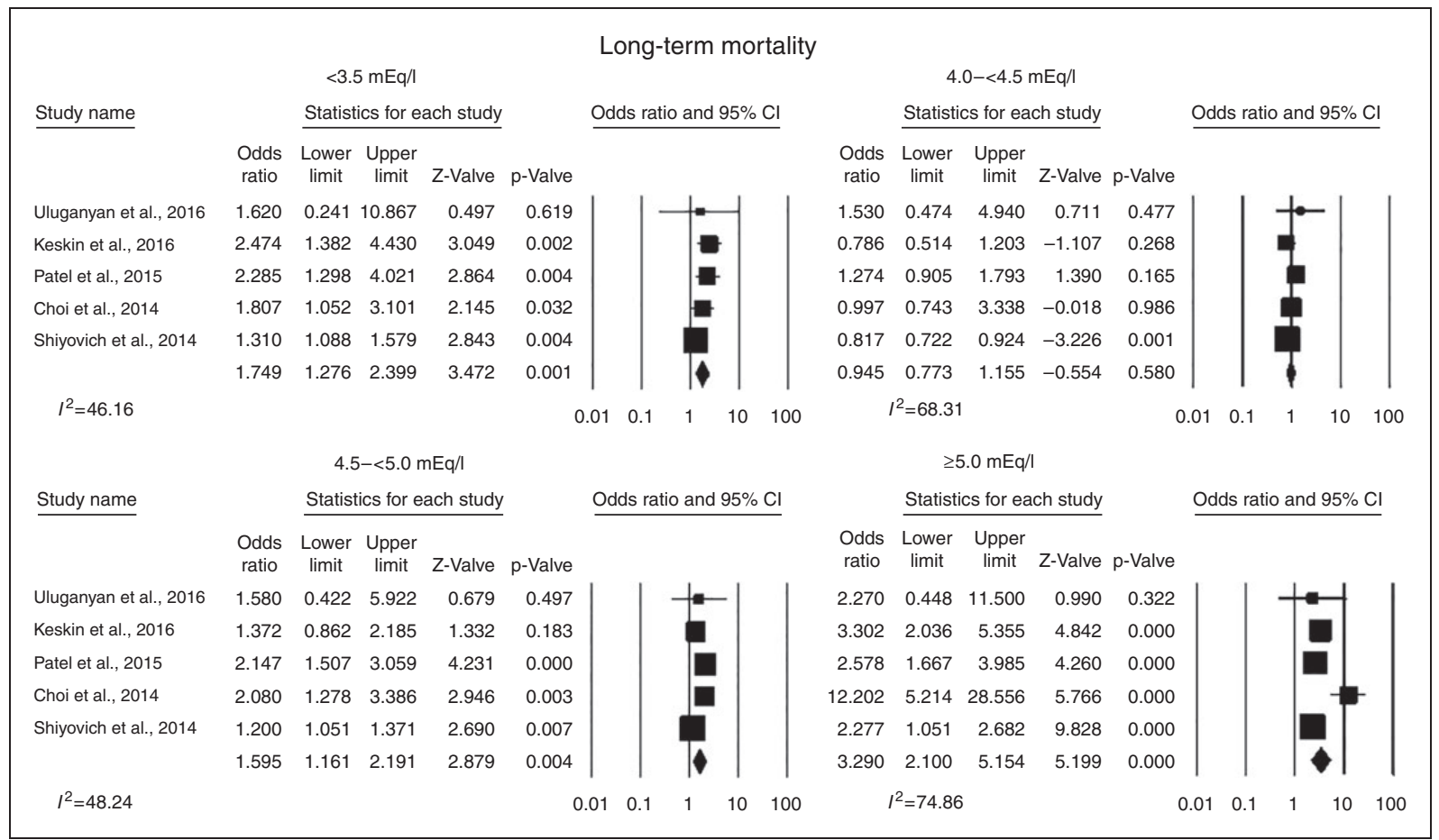

Figure 3. Pooled odds ratios (random effects) of long-term mortality associated with serum potassium concentration relative to category of $3.5-<4.0 \mathrm{mEq} / \mathrm{l}$.

concentrations. Madias et al. ${ }^{13}$ found a significantly higher number of VFs in the group of less than $3.5 \mathrm{mEq} / \mathrm{L}$ but not a significantly higher occurrence of VT compared with higher SPC. Su et al. ${ }^{32}$ and Higham et al. $^{37}$ both found a higher number of malignant arrhythmia and VF in patients with SPCs of less than $3.5 \mathrm{mEq} / \mathrm{L}$, and Fiol Sala et al. ${ }^{12}$ and Maciejewski et al. ${ }^{34}$ confirmed these findings for VF and for VF, VT and atrial fibrillation, with slightly different SPC categories of less than 3.6 and less than $4.0 \mathrm{mEq} / \mathrm{L}$, respectively. Except for Higham et al., ${ }^{37}$ all studies used single admission SPC. Some other studies used a SPC classification that did not match the common categorisation. ${ }^{17,30,36}$

Among the six studies that used a classification of SPC in five or seven categories, four studies reported the highest rates of VA in patients with SPCs less than $3.0 \mathrm{mEq} / \mathrm{L}^{9,28}$ or less than $3.5 \mathrm{mEq} / \mathrm{L} .{ }^{15,16}$ In contrast, in the studies from Choi et al. ${ }^{10}$ and $\mathrm{Ma}$ et al., ${ }^{19}$ patients with SPCs of $5.0 \mathrm{mEq} / \mathrm{L}$ or greater had the highest rates of VA occurrence. Multivariable regression analyses revealed a significantly increased VA risk for patients with SPCs less than $3.5 \mathrm{mEq} / \mathrm{L}$ in the study by Keskin et al., ${ }^{28}$ whereas Ma et al., ${ }^{19}$ Uluganyan et al. $^{16}$ and Choi et al. ${ }^{10}$ found no significantly increased risk. Goyal et al. ${ }^{9}$ showed a higher odds for $\mathrm{SPC}$ of less than $3.5 \mathrm{mEq} / \mathrm{L}$ only when single admission SPC was used for the analysis, but not when mean SPC was analysed.
Six studies were included in the meta-analysis. ${ }^{9,10,15,16,19,28}$ The SPC category of 3.5 to $4.0 \mathrm{mEq} / \mathrm{L}$ or less was used as the reference category. Goyal et al. ${ }^{9}$ and Keskin et al. ${ }^{28}$ provided more than five SPC categories. In order to fit the required number of categories, both the highest and lowest categories were combined with the next lower or next higher category, respectively. In two studies, 9,16 adjusted ORs were used as effect sizes, whereas Ma et al. ${ }^{19}$ provided adjusted HRs and Patel et al. ${ }^{15}$ and Choi et al. ${ }^{10}$ reported unadjusted numbers of events. Keskin et al. ${ }^{28}$ used a different reference category. In order to include all studies in the meta-analysis, the unadjusted number of deaths from the studies of $\mathrm{Ma}$ et al. ${ }^{19}$ and Keskin et al. ${ }^{28}$ was used in the analysis.

For SPCs of less than $3.5 \mathrm{mEq} / \mathrm{L}$ a significantly higher pooled OR (1.61, 95\% CI 1.31-1.97) was found compared with SPCs of 3.5 to less than $4.0 \mathrm{mEq} / \mathrm{L}$ and significantly lower ORs were detected for SPCs of 4.0 to less than $4.5 \mathrm{mEq} / \mathrm{L}$ and greater than $5.0 \mathrm{mEq} / \mathrm{L}$ (see Figure 4).

No heterogeneity $\left(I^{2}=0 \%\right)$ was found in two of the models. The pooled models on SPCs of 4.5 to less than $5.0 \mathrm{mEq} / \mathrm{L}$ and greater than $5.0 \mathrm{mEq} / \mathrm{L}$ indicated substantial heterogeneity $\left(I^{2}=55 \%\right.$ and $I^{2}=70 \%$, respectively). As the observed heterogeneity may be associated with the differences regarding SPC measurement, separate analyses were run for studies using admission SPCs $^{9,15,16}$ or mean SPCs. ${ }^{9,10,19,28}$ Within SPCs of less 


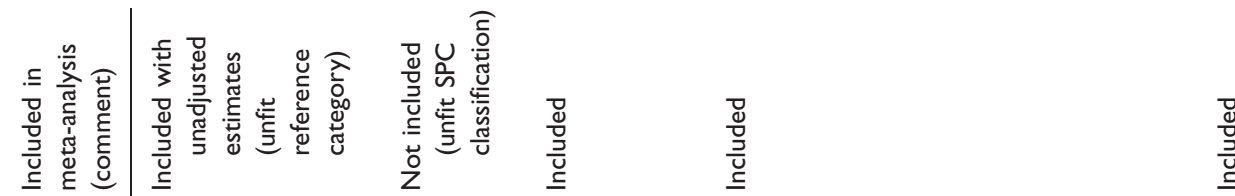

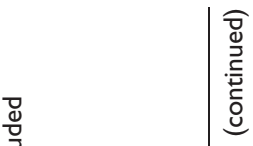

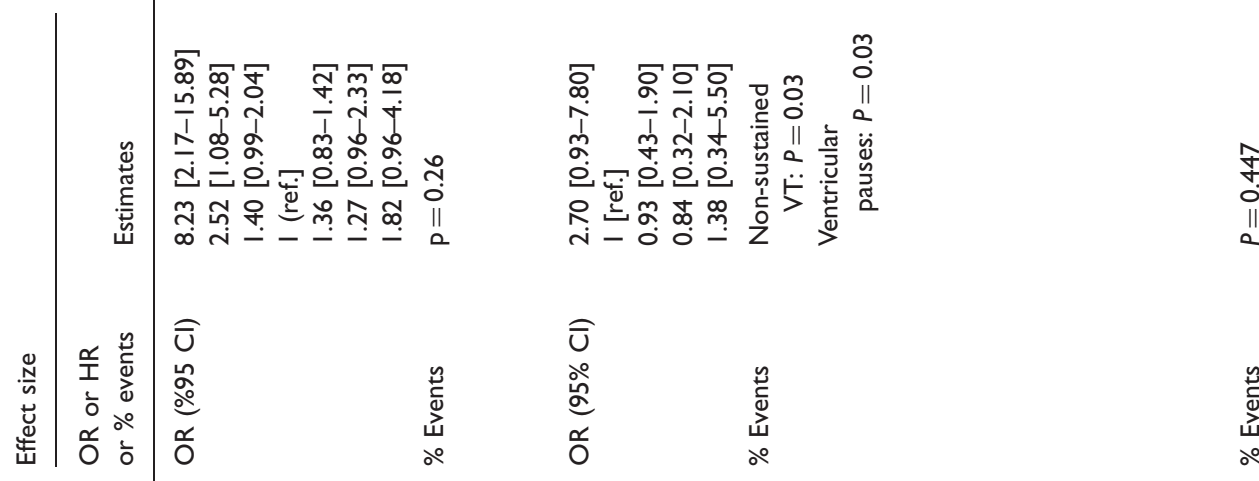

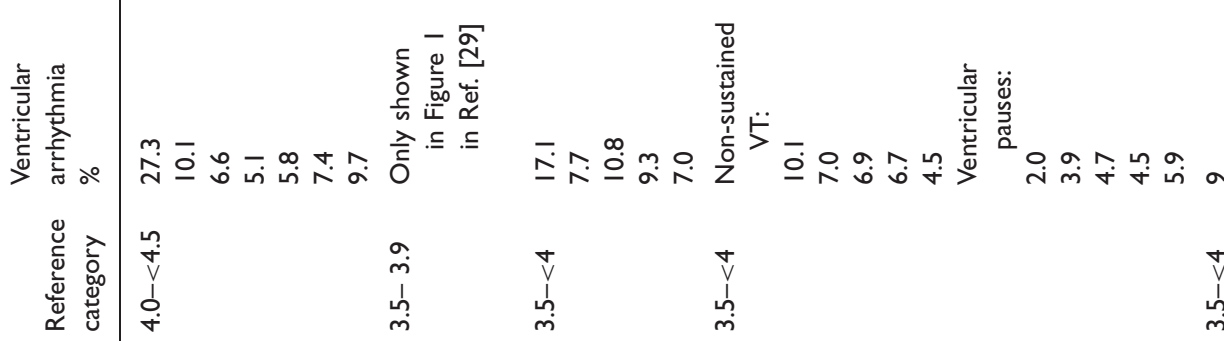

玄 중

之离总

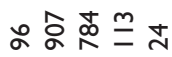

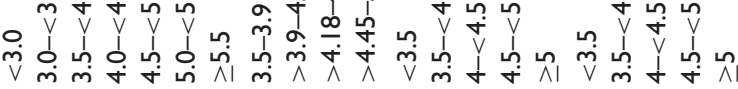

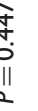

岇

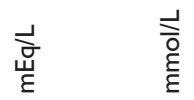

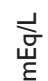

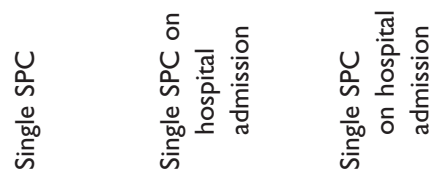

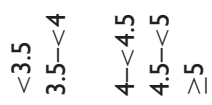

$\stackrel{\vec{v}}{\mathrm{E}}$

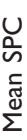

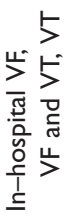

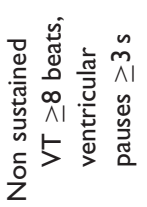

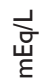

뭉 믄

든

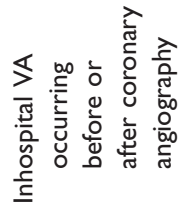

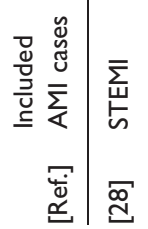

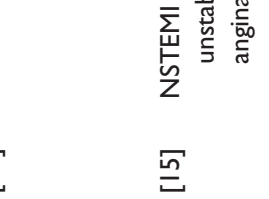

离点

믄 


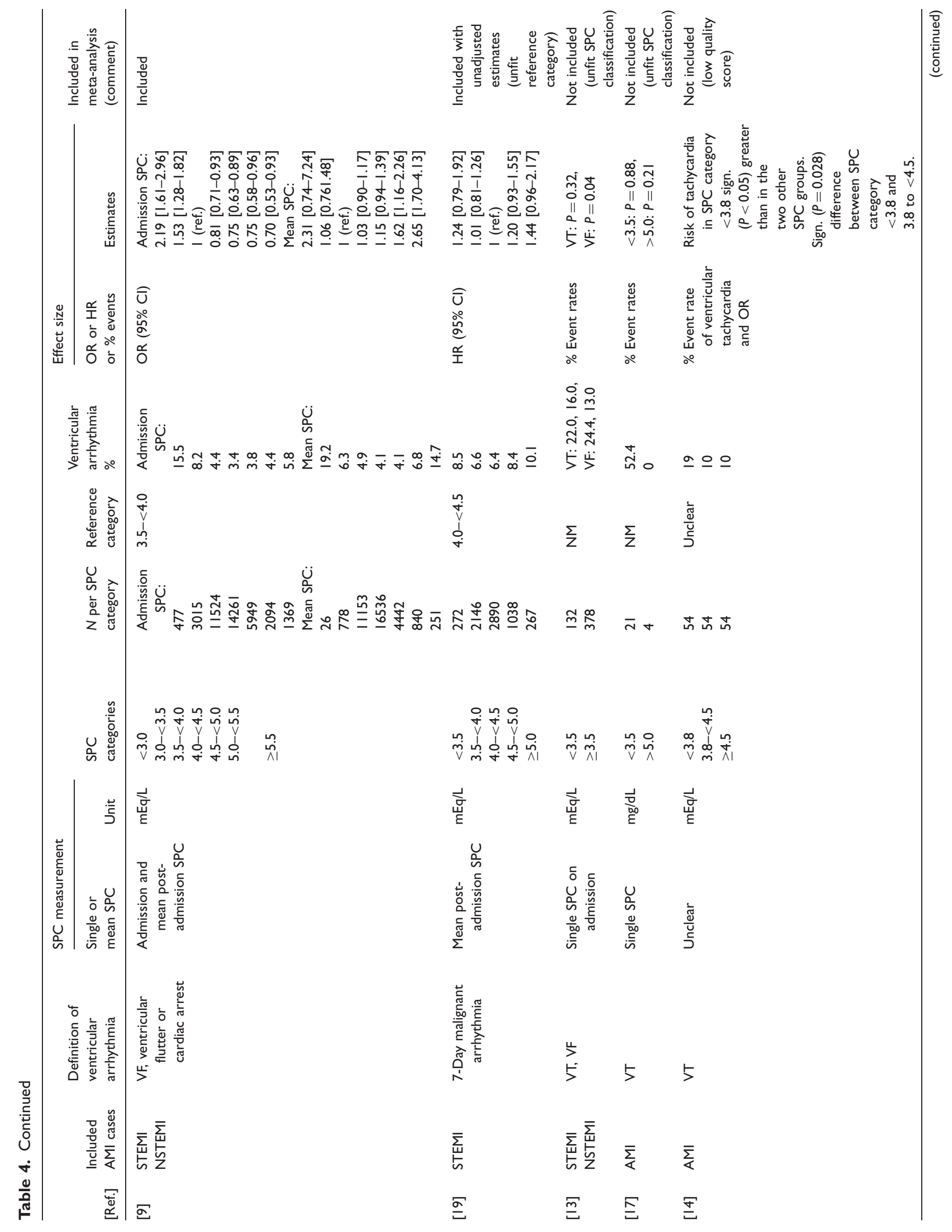




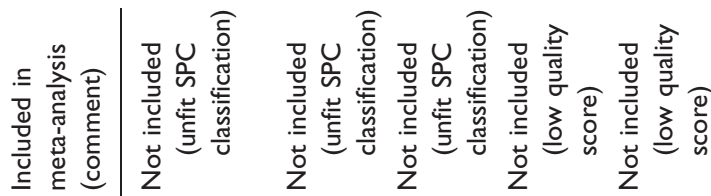

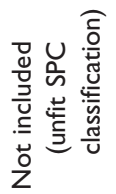

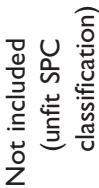

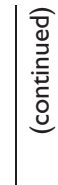

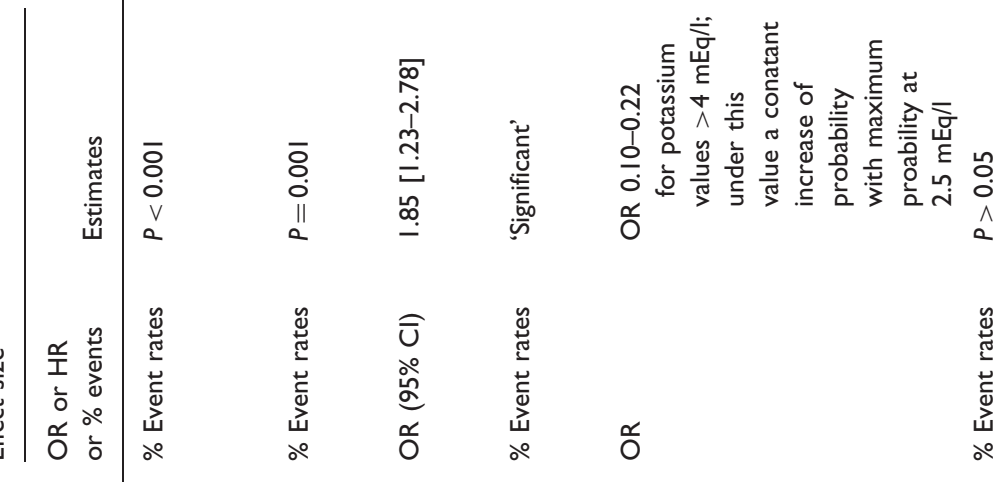

$\sum$

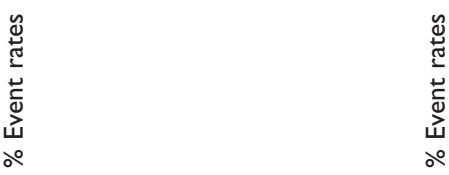

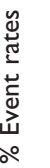

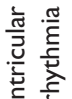

竞旁

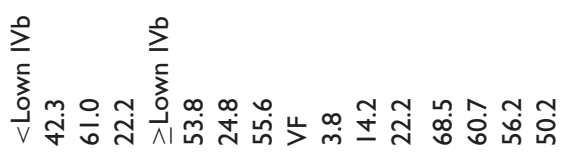

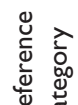

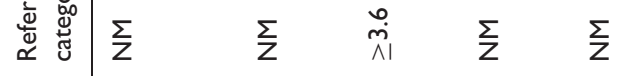

$\sum$

$\sum$

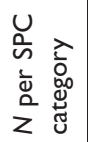

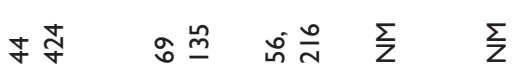

$\stackrel{\sim}{\bar{\Psi}}$

$\sum$

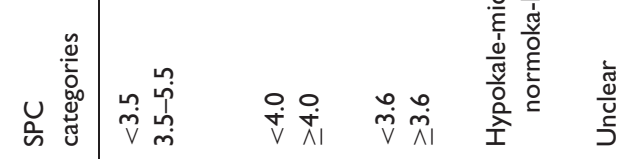

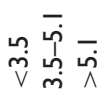

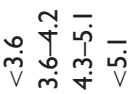

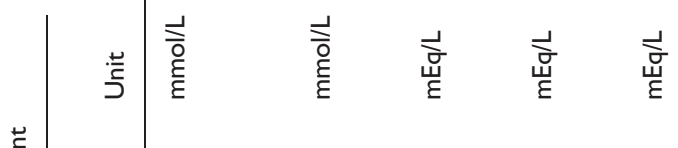

$\stackrel{5}{\stackrel{5}{\circ}}$

$\stackrel{๖}{\stackrel{े}{\circ}}$

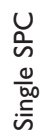

$u$
0
0
$\frac{0}{60}$
$i=0$

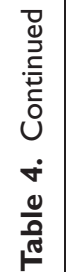

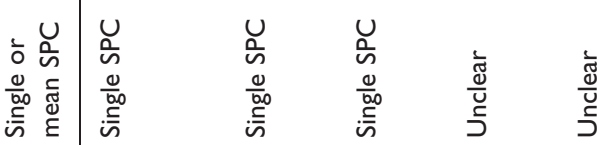

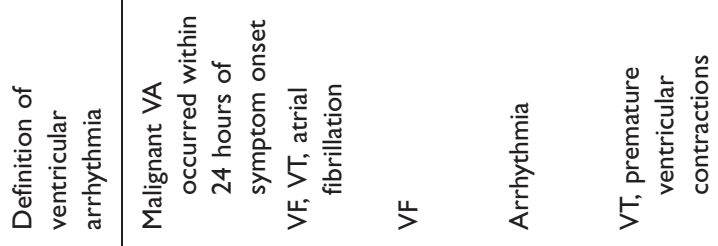

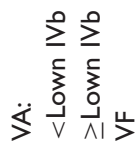

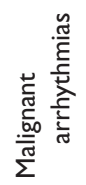

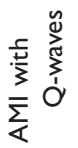

$\bar{\Sigma}$

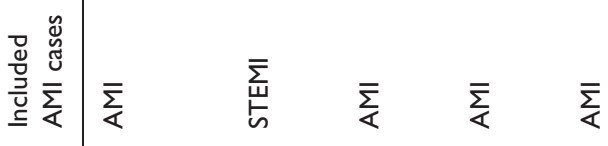

只

్ㅠㅁ 
than $3.5 \mathrm{mEq} / \mathrm{L}$ in both subgroups a significantly increased pooled risk was found compared with the reference SPC. In contrast, the pooled OR among SPCs of less than 4.0 to less than $4.5 \mathrm{mEq} / \mathrm{L}$ was lower and significant in the studies with an admission SPC measurement (OR 0.84, 95\% CI 0.75-0.95) compared with the pooled OR in the studies with a mean SPC measurement (OR 0.93, 95\% CI 0.81-1.08). In the SPC group 4.5 to $5.0 \mathrm{mEq} / \mathrm{L}$ the results were completely different, with a lower pooled OR of $0.80(95 \%$ CI 0.69-0.92) among studies with an admission SPC measurement and a higher pooled OR of 1.15 (95\% CI 0.99 1.33) found among studies with a mean SPC measurement. A significant difference between the subgroups was found for SPCs of $5.0 \mathrm{mEq} / \mathrm{L}$ or greater with a significantly decreased pooled OR of $0.72(95 \%$ CI $0.60-0.85$ ) in studies with an admission SPC measurement in contrast to a significantly increased pooled OR of 1.61 (95\% CI 1.23-2.09) in studies with a mean SPC measurement. No indication of heterogeneity $\left(I^{2}<34 \%\right)$ was found in the analyses above.

\section{Discussion}

This systematic review and meta-analysis showed that SPCs less than $3.5 \mathrm{mEq} / \mathrm{L}$ and $4.5 \mathrm{mEq} / \mathrm{L}$ or greater in patients with AMI were associated with a higher risk of short-term mortality compared with SPCs of 3.5 to less than $4.0 \mathrm{mEq} / \mathrm{L}$. Likewise, a U-shaped association of SPC and long mortality was found, with the exception that patients with SPCs of 4.0 to less than $4.5 \mathrm{mEq} / \mathrm{L}$ had a similar risk to patients with SPCs of 3.5 to less than $4.0 \mathrm{mEq} / \mathrm{L}$. In addition, SPCs less than $3.5 \mathrm{mEq} / \mathrm{L}$ were associated with an increased risk of VA.

A most interesting result is the finding that the association between SPC and outcomes seems to be U-shaped and that recommendations simply to increase SPC in AMI patients may therefore be misleading. Our meta-analysis indicates that SPCs of $4.5 \mathrm{mEq} / \mathrm{L}$ and beyond negatively affect post-AMI survival. This finding may be at least partly explained by the association of hyperkalemia with reduced ventricular excitability that can result in complete heart block and sinus arrest. ${ }^{38,39}$ Higher SPCs may also indicate renal failure, which constitutes a major risk factor for post-AMI survival. ${ }^{40}$ However, most of the studies included in the meta-analysis have considered renal function as a confounder and SPCs of $5 \mathrm{mEq} / \mathrm{L}$ or greater remained significantly associated with higher mortality rates after adjustment. ${ }^{9,10,15,28}$

Overall, the present systematic review and meta-analysis confirmed that $\mathrm{SPC}$ of less than $3.5 \mathrm{mEq} / \mathrm{L}$ was negatively associated with survival and VA after AMI. This is well known among the medical community and part of all AMI treatment guidelines. ${ }^{5-8}$ 


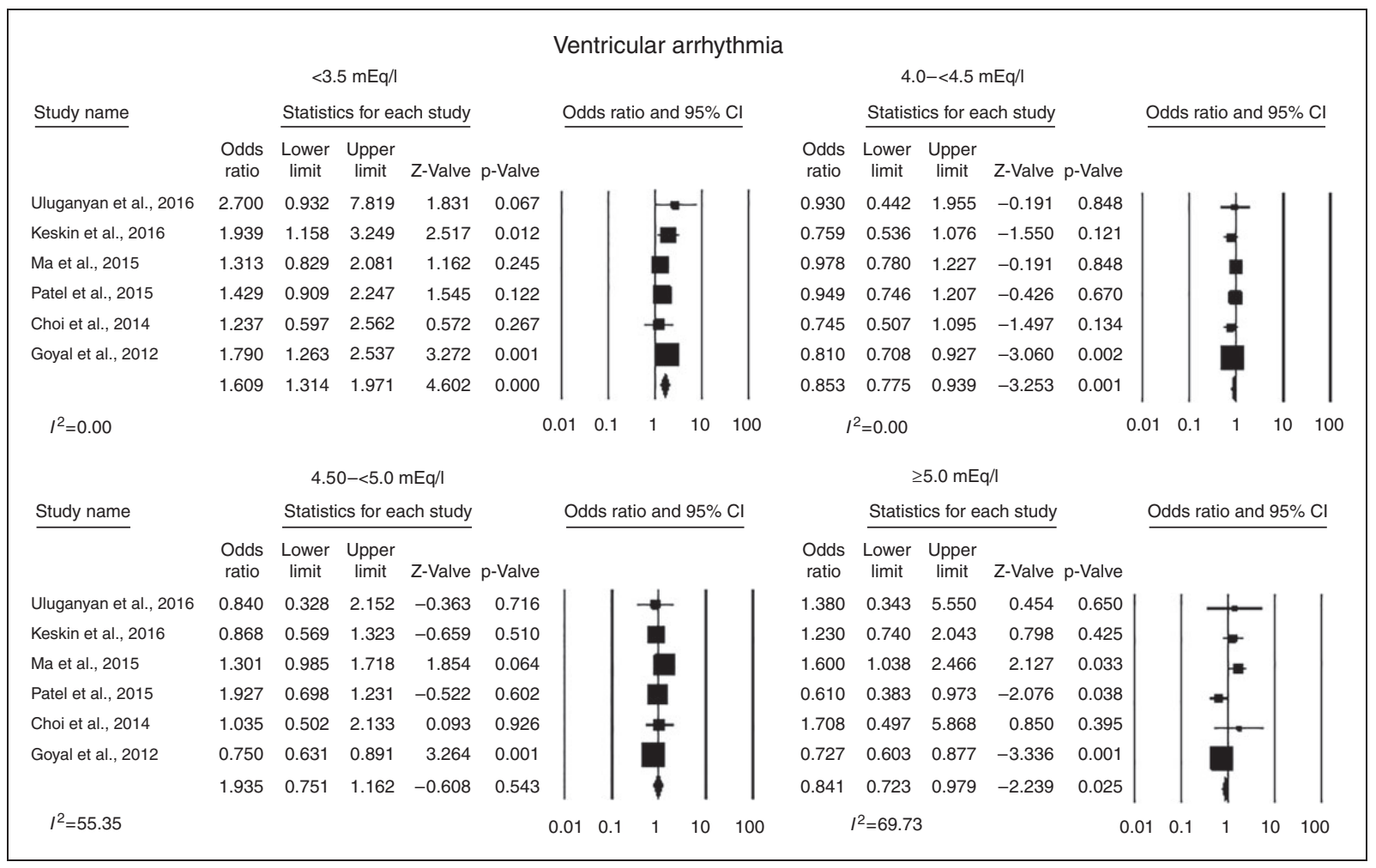

Figure 4. Pooled odds ratios (random effects) of ventricular arrhythmia associated with serum potassium concentration relative to category of $3.5-<4.0 \mathrm{mEq} / \mathrm{l}$.

However, the present analysis also confirmed this finding in more recent studies conducted in the 'reperfusion era', in which standard AMI treatment includes early invasive treatment and routine use of beta-blockers. Beta-blockers raise SPC by blocking epinephrineinduced depression of SPC through beta-receptor stimulation. ${ }^{41,42}$ A considerable number of studies on the association between SPC and VA were performed before the reperfusion era ${ }^{12,17,27,35-37}$ or analysed data were collected before the year $1990 .{ }^{13}$ However, the management of both ST-segment elevation myocardial infarction (STEMI) and non-STEMI has advanced substantially over the past 20 years. The application of beta-blockers in acute coronary syndrome (ACS), reperfusion and antiplatelet treatment has decreased the risk of VF in ACS by at least one third. ${ }^{43,44}$ Practice guidelines, including recommendations on SPC in the management of AMI, are based on these older studies that might not apply to contemporarilytreated AMI patients. Almost all of these early studies have investigated the association of hypo and hyperkalemia and VA using a dichotomous classification of SPC. In our meta-analysis we aimed to investigate the effects of a more finely graduated SPC classification, and therefore we excluded earlier studies. The analysis of this more detailed SPC classification yielded interesting results. Our meta-analysis confirmed the well-described association of SPC of less than $3.5 \mathrm{mEq} / \mathrm{L}$ and the occurrence of VA, but also yielded conflicting results in terms of higher SPC depending on the type of SPC collection. While the pooled risk of VA in patients with SPC of 4.5 to less than $5.0 \mathrm{mEq} / \mathrm{L}$ and $5.0 \mathrm{mEq} / \mathrm{L}$ or greater was decreased in studies using single admission SPC, $, 15,16$ it was significantly increased in studies using a mean value of several SPC measurements during hospitalisation. ${ }^{9,10,19,28}$ Goyal et al. ${ }^{9}$ have already observed a similar effect in their study in which they reported results for admission SPC as well as mean SPC. According to American College of Cardiology/American Heart Association STEMI guidelines, aggressively normalising SPC to greater than $4.0 \mathrm{mEq} / \mathrm{L}$ in post-AMI patients with VA is recommended. ${ }^{7}$ When extracellular SPC falls below $3.5 \mathrm{mEq} / \mathrm{L}$, the risk of $\mathrm{VT}$ and $\mathrm{VF}$ is increased in patients with AMI due to a number of electrophysiological changes. ${ }^{45}$ Efforts to normalise SPC in hypokalemic patients combined with medical and drug treatment affecting potassium homeostasis might cause the SPC subsequently to exceed $4.5 \mathrm{mEq} / 1{ }^{46,47}$ Thus hyperkalemia following hypokalemia could explain why studies using the mean SPC found significantly increased risks of VA in patients with SPC of 4.5 
to less than $5.0 \mathrm{mEq} / 1$ and $5.0 \mathrm{mEq} / \mathrm{L}$ or greater, while those using the admission SPC did not. In addition, apart from the information that VA occurred during hospital stay, studies did not report the exact time of VA onset. The mean SPC might contain SPC measurements that were taken before as well as after the onset of VA. Thus this would not allow reliable conclusions to be drawn on the relationship of mean SPC and VA. To conclude, using the mean SPC might overestimate the risk of VA in patients with SPC of 4.5 to less than $5.0 \mathrm{mEq} / \mathrm{L}$ and $5.0 \mathrm{mEq} / \mathrm{L}$ or greater.

The present systematic review and meta-analysis provided an overview on available scientific evidence regarding SPC and AMI outcomes. A strength of this paper is the inclusion of results of recent and high-quality studies from the reperfusion era, which were not considered in the available practice guidelines for AMI treatment so far. The meta-analysis enabled an increase of statistical power in the extremes of SPC that were often characterised by small numbers of events in the single studies.

However, several limitations should be considered. The studies combined in the meta-analyses on the different outcomes have slightly different study characteristics e.g. in terms of AMI type, follow-up period, time and frequency of SPC assessment. Due to the small number of retrieved studies it was not always possible to perform sensitivity analyses to estimate the effects of these heterogeneous characteristics on the pooled effect sizes. Moreover, it was not possible to include the confounder-adjusted estimates from all studies in the metaanalyses, because studies used HRs as effect sizes instead of ORs or different reference categories. The inclusion of the unadjusted results may have led to an overestimation of the pooled effects. Thus the pooled effects should be interpreted with caution. We have assessed the quality of the studies using a summary score with unweighted items, which may be difficult to interpret and the definition of the threshold for exclusion may be arbitrary.

The results of this systematic review and meta-analysis support the guideline recommendation that SPC should not be lower than $3.5 \mathrm{mEq} / \mathrm{L}$ in patients with AMI in order to improve short and long-term survival and to avoid VA. However, guideline recommendations that SPC should be at least $4.5 \mathrm{mEq} / \mathrm{L}$ or higher in AMI patients are challenged by the scientific evidence from the studies included in this systematic review and meta-analysis. The results indicate that higher SPC concentrations may be adversely associated with short and long-term survival. The reservation must be made, however, that due to the high heterogeneity among existing studies and the limitations mentioned above, further research is necessary to confirm the need to change clinical practice guidelines.

\section{Author contribution}

MGC, IK, UA and CM conceived the study. MGC conducted the literature search. Titles, abstracts and articles were screened by MGC, IK, UA and LD. Data extraction was performed by MGC, IK and UA. IK performed the statistical analysis. MGC, IK and UA drafted the manuscript. $\mathrm{CM}$ and LD critically revised the manuscript. All authors approved the final manuscript and agree to be accountable for all aspects of the work ensuring integrity and accuracy. All authors take responsibility for all aspects of the reliability and freedom from bias of the data presented and their discussed interpretation.

\section{Declaration of conflicting interests}

The author(s) declared no potential conflicts of interest with respect to the research, authorship, and/or publication of this article.

\section{Funding}

The author(s) received no financial support for the research, authorship, and/or publication of this article.

\section{References}

1. Schaefer TJ and Wolford RW. Disorders of potassium. Emerg Med Clin North Am 2005; 23: 723-747, viii-ix.

2. Clausen T. Hormonal and pharmacological modification of plasma potassium homeostasis. Fundam Clin Pharmacol 2010; 24: 595-605.

3. Alfonzo AV, Isles C, Geddes C, et al. Potassium disorders - clinical spectrum and emergency management. Resuscitation 2006; 70: 10-25.

4. Heerspink HJ, Gao P, de Zeeuw D, et al. The effect of ramipril and telmisartan on serum potassium and its association with cardiovascular and renal events: results from the ONTARGET trial. Eur J Prev Cardiol 2014; 21 : 299-309.

5. Cohn JN, Kowey PR, Whelton PK, et al. New guidelines for potassium replacement in clinical practice: a contemporary review by the National Council on Potassium in Clinical Practice. Arch Intern Med 2000; 160: 2429-2436.

6. Zipes DP, Camm AJ, Borggrefe M, et al. ACC/AHA/ESC 2006 Guidelines for management of patients with ventricular arrhythmias and the prevention of sudden cardiac death: a report of the American College of Cardiology/ American Heart Association Task Force and the European Society of Cardiology Committee for Practice Guidelines (Writing Committee to Develop guidelines for management of patients with ventricular arrhythmias and the prevention of sudden cardiac death) developed in collaboration with the European Heart Rhythm Association and the Heart Rhythm Society. Europace 2006; 8: 746-837.

7. Antman EM, Anbe DT, Armstrong PW, et al. ACC/AHA Guidelines for the management of patients with STelevation myocardial infarction - executive summary. A report of the American College of Cardiology/ American Heart Association Task Force on Practice Guidelines (Writing Committee to revise the 1999 
guidelines for the management of patients with acute myocardial infarction). J Am Coll Cardiol 2004; 44: 671-719.

8. Macdonald JE and Struthers AD. What is the optimal serum potassium level in cardiovascular patients? $\mathrm{J} \mathrm{Am}$ Coll Cardiol 2004; 43: 155-161.

9. Goyal A, Spertus JA, Gosch K, et al. Serum potassium levels and mortality in acute myocardial infarction. JAMA 2012; 307: 157-164.

10. Choi JS, Kim YA, Kim HY, et al. Relation of serum potassium level to long-term outcomes in patients with acute myocardial infarction. Am J Cardiol 2014; 113: 1285-1290.

11. Shiyovich A, Gilutz H and Plakht Y. Serum potassium levels and long-term post-discharge mortality in acute myocardial infarction. Int J Cardiol 2014; 172: e368-e370.

12. Fiol Sala M IJJ, Benito Vales S, Gutierrez Marti R, et al. Hipocaliemia y fibrilacion ventricualar primaria en pacientes con infarcto agudo de miocardio. Med Intentiva 1993; 17: 276-279.

13. Madias JE, Shah B, Chintalapally G, et al. Admission serum potassium in patients with acute myocardial infarction: its correlates and value as a determinant of in-hospital outcome. Chest 2000; 118: 904-913.

14. Pourmoghaddas A, Shemirani $\mathrm{H}$ and Garakyaraghi M. Association of serum potassium level with ventricular tachycardia after acute myocardial infarction. $A R Y A$ Atheroscler 2012; 8: 79-81.

15. Patel RB, Tannenbaum S, Viana-Tejedor A, et al. Serum potassium levels, cardiac arrhythmias, and mortality following non-ST-elevation myocardial infarction or unstable angina: insights from MERLIN-TIMI 36. Eur Heart J Acute Cardiovasc Care 2015; 6: 18-25.

16. Uluganyan M, Ekmekci A, Murat A, et al. Admission serum potassium level is associated with in-hospital and long-term mortality in ST-elevation myocardial infarction. Anatol J Cardiol 2016; 16: 10-15.

17. Ognibene A, Ciniglio R, Greifenstein A, et al. Ventricular tachycardia in acute myocardial infarction: the role of hypophosphatemia. South Med J 1994; 87: 65-69.

18. Krijthe BP, Heeringa J, Kors JA, et al. Serum potassium levels and the risk of atrial fibrillation: the Rotterdam Study. Int J Cardiol 2013; 168: 5411-5415.

19. Ma W, Liang Y, Zhu J, et al. Serum potassium levels and short-term outcomes in patients with ST-segment elevation myocardial infarction. Angiology 2016; 67: 729-736.

20. Moher D, Liberati A, Tetzlaff J, et al.; The PRISMA Group. Preferred Reporting Items for Systematic Reviews and Meta-Analyses: the PRISMA Statement. PLoS Med 2009; 6: e1000097.

21. Downs $\mathrm{SH}$ and Black N. The feasibility of creating a checklist for the assessment of the methodological quality both of randomised and non-randomised studies of health care interventions. J Epidemiol Commun Health 1998; 52: 377-384.

22. Higgins JP, Altman DG, Gotzsche PC, et al. The Cochrane Collaboration's tool for assessing risk of bias in randomised trials. BMJ 2011; 343: d5928.
23. Borenstein M, Hedges LV, Higgins JPT, et al. Software, in Introduction to Meta-Analysis. Chichester, UK: John Wiley \& Sons Ltd., 2009.

24. Higgins JPT and Green S. Cochrane Handbook for Systematic Reviews of Interventions, version 5.1.0 (updated March 2011) The Cochrane Collaboration, 2011. www.handbook.cochrane.org (accessed 1 June 2017).

25. Verma S, Agarwal YB, Sharma SK, et al. Dyselectrolytaemia in acute myocardial infarction. JIACM 2015; 16: 201-203.

26. Kiranmai P. Serial estimation of serum magnesium, calcium, sodium and potassium levels in myocardial infarction. Int J Pharm Bio Sci 2013; 4: 1190-1195.

27. Lettieri B, Chiefari M, Nespoli M, et al. [Hypomagnesemia and hypokalemia as risk factors of arrhythmia in acute phase myocardial infarction]. Minerva Anestesiol 1991; 57: 335-339.

28. Keskin M, Kaya A, Tatlisu MA, et al. The effect of serum potassium level on in-hospital and long-term mortality in ST elevation myocardial infarction. Int J Cardiol 2016; 221: 505-510.

29. Grodzinsky A, Goyal A, Gosch K, et al. Prevalence and prognosis of hyperkalemia in patients with acute myocardial infarction. Am J Med 2016; 129: 858-865.

30. Shlomai G, Berkovitch A, Pinchevski-Kadir S, et al. The association between normal-range admission potassium levels in Israeli patients with acute coronary syndrome and early and late outcomes. Medicine (Baltimore) 2016; 95: e3778.

31. Huang YL and Hu ZD. Lower mean corpuscular hemoglobin concentration is associated with poorer outcomes in intensive care unit admitted patients with acute myocardial infarction. Ann Transl Med 2016; 4: 190.

32. Su J, Fu X, Tian Y, et al. Additional predictive value of serum potassium to thrombolysis in myocardial infarction risk score for early malignant ventricular arrhythmias in patients with acute myocardial infarction. Am J Emerg Med 2012; 30: 1089-1094.

33. Nicolaou VN, Papadakis JE, Chrysohoou C, et al. The prognostic significance of serum glucose levels after the onset of ventricular arrhythmia on in-hospital mortality of patients with acute coronary syndrome. Rev Diabet Stud 2008; 5: 47-51.

34. Maciejewski P, Bednarz B, Chamiec T, et al. Acute coronary syndrome: potassium, magnesium and cardiac arrhythmia. Kardiol Pol 2003; 59: 402-407.

35. Pohl W, Mory P, Nurnberg M, et al. [Serum magnesium, serum potassium and arrhythmia profile in patients with acute myocardial infarct]. Wien Klin Wochenschr 1993; 105: 163-166.

36. Friedensohn A, Faibel HE, Bairey O, et al. Malignant arrhythmias in relation to values of serum potassium in patients with acute myocardial infarction. Int $J$ Cardiol 1991; 32: 331-338.

37. Higham PD, Adams PC, Murray A, et al. Plasma potassium, serum magnesium and ventricular fibrillation: a prospective study. Q J Med 1993; 86: 609-617. 
38. Gettes LS. Electrolyte abnormalities underlying lethal and ventricular arrhythmias. Circulation 1992; 85: I70-I76.

39. Podrid PJ. Potassium and ventricular arrhythmias. Am J Cardiol 1990; 65: 33E-44E; discussion 52E.

40. Bae EH, Lim SY, Cho KH, et al. GFR and cardiovascular outcomes after acute myocardial infarction: results from the Korea Acute Myocardial Infarction Registry. Am J Kidney Dis 2012; 59: 795-802.

41. Traub YM, Rabinov M, Rosenfeld JB, et al. Elevation of serum potassium during beta blockade: absence of relationship to the renin-aldosterone system. Clin Pharmacol Ther 1980; 28: 765-768.

42. Johansson BW and Dziamski R. Malignant arrhythmias in acute myocardial infarction. Relationship to serum potassium and effect of selective and non-selective betablockade. Drugs 1984; 28(Suppl 1): 77-85.

43. Goldberg RJ, Yarzebski J, Spencer FA, et al. Thirty-year trends (1975-2005) in the magnitude, patient characteristics, and hospital outcomes of patients with acute myocardial infarction complicated by ventricular fibrillation. Am J Cardiol 2008; 102: 1595-1601.

44. Avezum A, Piegas LS, Goldberg RJ, et al. Magnitude and prognosis associated with ventricular arrhythmias in patients hospitalized with acute coronary syndromes (from the GRACE Registry). Am J Cardiol 2008; 102: 1577-1582.

45. Osadchii OE. Mechanisms of hypokalemia-induced ventricular arrhythmogenicity. Fundam Clin Pharmacol 2010; 24: 547-559.

46. Gennari FJ. Hypokalemia. N Engl J Med 1998; 339: 451-458.

47. Crop MJ, Hoorn EJ, Lindemans J, et al. Hypokalaemia and subsequent hyperkalaemia in hospitalized patients. Nephrol Dial Transplant 2007; 22: 3471-3477. 